\title{
Sustainable Development Goals: relevance to maternal and child health in Nepal
}

\author{
Pramod R Regmi ${ }^{1,2^{*}}$, Edwin van Teijlingen ${ }^{3-5}$, Vanora Hundley ${ }^{3}$, Padam Simkhada ${ }^{4-6}$, Sheetal Sharma ${ }^{3}$, Preeti \\ Mahato $^{3}$ \\ ${ }^{1}$ Faculty of Health and Social Sciences, Bournemouth University, UK ${ }^{2}$ Chitwan Medical College, Tribhuvan University, Nepal ${ }^{3}$ Centre for Midwifery, Maternal and \\ Perinatal Health, Faculty of Health and Social Sciences, Bournemouth University, UK ${ }^{4}$ Manmohan Memorial Institute of Health Sciences, Tribhuvan University, \\ Nepal ${ }^{5}$ Nobel College, Pokhara University, Nepal ${ }^{6}$ Centre for Public Health, Liverpool John Moores University, UK
}

In 2000, the United Nations (UN) adopted eight MillenniumDevelopment Goals (MDGs), three of these focused on health although several other MDGs included health-related components such as nutrition and sanitation (1). Overall progress towards the MDGs has been inspiring and specifically the health-related targets, e.g. MDG4 (reduce child mortality), MDG5 (improve maternal health) and MDG6 (combat HIV/ AIDS, malaria and other diseases) have been promising. For example, the global maternal mortality ratio (MMR) has fallen by 44\% (from 341 in 2000 to 216 per 100,000 live births in 2015) and under-five mortality in the same period dropped by 53\% (2). Despite these achievements, the world has failed to meet these MDG targets for both maternal mortality and under-five mortality, a fact recognised by maternal health practitioners, policy-makers and researchers across the globe (3). Moreover, progress has not advanced

Received:

23 January 2016

Revised:

01 February 2016

Accepted:

10 February 2016

\section{*Correspondence: pregmi@bournemouth.ac.uk Faculty of Health and Social Sciences, Bournemouth University, England, UK} equally across the globe, for instance, improvements in MMR have been better in Southeast Asia (69\% reduction) and the Western Pacific (64\% reduction) (2).

After 15 years the MDGs reached their target date in 2015, and the global community has moved onto a new agenda, namely that of the Sustainable Development Goals (SDGs) (4). The SDGs integrate three dimensions (social, economic and environment) of sustainable development for people, the planet, prosperity, peace and partnerships. With high ambitions and unprecedented scope, Sustainable Development has 17 goals and 169 targets with one integrated goal "ensure healthy lives and promote wellbeing for all at all ages." These agendas build upon and extend the MDGs to tackle the gap between the MDGs' targets and reality; consequently this is an important time for all of us to reflect, celebrate our achievements and move forward with lessons learnt and evidence-based practice. The landmark conference 'Global strategy for Women's, Children's and Adolescents' health hosted in Mexico City in October 2015 discussed the unfinished agendas of the MDGs. It specifically focused on increasing equitable coverage of quality health care and provision of integrated services delivered through a gradually strengthened primary health care system (5).

The SDGs devote 13 health-related targets focusing on population health and wellbeing issues including maternal and child health, communicable diseases (including HIV), non-communicable diseases, substance use, traffic accidents, universal access to sexual and reproductive health, and sanitation. There is no doubt that progress towards these targets will improve health outcomes. It is estimated that achievement of these health-related targets for child, maternal, communicable and non-communicable diseases would result in an increased global average life expectancy of around four years by 2030 (2). Several other agendas under targets such as nutrition, childhood development, reducing violence against women, disability, addressing forced marriage, safe drinking water and universal access to sexual and reproductive health and rights relate to health, reflecting the need to improve cross-cutting socio-economic and environmental issues.

Despite the decade-long political instability and residual political issues (6), Nepal was one of the few low and middle income countries (LMICs) that achieved several MDGs well before the 2015 deadline. There was been a significant decline (80\%; from 850 maternal deaths per 100,000 live births in 1990 to just 170 in 2010) in MMR in two decades time (7), although recent WHO (2015) estimates suggested a MMR of 258 per 100,000 live births (8). Similarly, the target for the under-five mortality rate (i.e. 54 per 1,000 live births) was achieved in 2011. However, inequality, exclusion and under-utilisation in health care service continues in many regions of Nepal. For instance, births assisted by skilled birth attendants (SBA) are 10.7\% for the poorest and $81.5 \%$ for the richest quintile (9). Similarly, mothers with no education have a higher under-five mortality (73 deaths per 1,000 live births) than those who completed the School Leaving Certificate (SLC) or a higher level of education (32 deaths per 1,000 live births) (9).

Nepal has made several efforts to address such inequities in health care. One example is the establishment of birthing centres (BCs), which act as initial institutional contact points for birth at a local health facility. It provides access, quality services and promotes institutional delivery for the marginalised population in the rural area. In recent years, there has been an increase in BCs, 1,134 as of July 2014, offering 24-hour intrapartum services thus providing access to people in remote villages in an effort to reduce the urbanrural divide (10). However, Nepal must ensure a continuum of health care across all level of services and care, all sections of society and over the life-cycle. 
With the creation of the Inter-Agency and Expert Group on SDG Indicators (IAEG-SDGs) by the UNs' Statistical Commission (11); the Declaration on Sustainable Development pays considerable attention to the systematic monitoring and reviewing of interventions at all levels. This group in essence is responsible for the global measurement of progress of the SDG indicators. Nepal should develop a measureable and time-bound indicator framework to track and review its own progress towards SDGs. Technical support from development partners should also play an important role in developing and boosting the monitoring capacity of Nepal. For instance, Davis and colleagues (12) proposed a two-track SDG measurement framework for 2030. The first, to monitor political goals (about 30 impact indicators) to assess overall progress regionally and globally. The secondly, to include a larger number of technical indicators to measure the means of implementation or processes towards each goal (300 indicators, or more) (13).

Being a signatory country of the Sustainable Development declaration, Nepal should attempt to turn the vision of the SDGs into reality. Maternal death in Nepal is still 43 times higher than in a high income country such as Sweden, while Nepali children are more than five times as likely to die before they reach five years of age than their regional counterparts in Sri Lanka (14). Many health problems in Nepal are still exacerbated by the under-utilisation of available resources; shortages of adequately trained personnel; underdeveloped infrastructure; poor public sector management; and weak intra and inter-sectoral co-ordination (15). We argue that continued technical and financial support from external development partners is necessary to sustain Nepal's achievements in maternal and child health and to further strengthen the health-service provision. We must take this opportunity to change Nepal through this sustainable development agenda.

\section{Competing interests}

The authors declare that they have no competing interests.

\section{References}

1. United Nations. 2015. The Millennium Development Goals Report 2015. New York: United Nations. Available: http://www.un.org/millenniumgoals/2015_MDG_ Report/pdf/MDG\%202015\%20rev\%20\%28July\%201\%29.pdf [Accessed January 10 2016].

2. World Health Organization. 2015. Health in 2015: from MDGs, Millennium Development Goals to SDGs, Sustainable Development Goals. Switzerland: World Health Organization. Available: http://www.who.int/gho/publications/mdgs-sdgs/en/ [Accessed January 102016 ].

3. van Teijlingen E, Hundley V, Matthews Z, Lewis G, Graham WJ, Campbell J, Ten Hoope-Bender P, Sheppard ZA\&Hulton L. 2014. Millennium Development Goals: All good things must come to an end, so what next? Midwifery, 30,1-2.

4. United Nations. 2015. Transforming our world: The 2030 agenda for sustainable development. New York: United Nations. Available: https://sustainabledevelopment. un.org/post2015/transformingourworld [Accessed January 10 2016].

5. Paudel YR. 2015. Unfinished MDG agenda highlighted at the first Global Maternal Newborn Health Conference. Health Prospect. 14, 18-19.

6. Simkhada P, Regmi PR, Pant PR., van Teijlingen ER\&Sathian B. 2015. Stipulating citizens' fundamental right to healthcare: Inference from the Constitution of Federal Republic of Nepal 2015. Nepal J Epidemiol, 5, 516-517.

7. National Planning Commission. 2013. Nepal Millennium Development Goals Progress Report 2013. Kathmandu: National Planning Commission.

8. WHO/UNICEF/UNFPA/World Bank Group/UN. 2015. Trends in maternal mortality: 1990 to 2015, Estimates by WHO, UNICEF, UNFPA, World Bank Group and the United Nations Population Division. Geneva: World Health Organization. Available: http://apps.who.int/iris/bitstream/10665/194254/1/9789241565141_eng. pdf?ua=1 [Accessed January 312016 ]

9. Ministry of Health and Population, New ERA, ICF International Inc. 2012. Nepal Demographic and Health Survey 2011. Kathmandu: Ministry of Health and Population, New ERA, and ICF International, Calverton, Maryland.

10. Family Health Division, Department of Health Services. 2014. Results from Assessing Birthing Centers in Nepal. Kathmandu: Family Health Division and Ministry of Health and Population.

11. United Nations Statistical Commission. 2015. Available: http://unstats.un.org/sdgs/iaeg-sdgs/ [Accessed January 20 2016].

12. Davis A, Matthews, Z, SzaboS, Fogstad, H. 2015. Measuring the SDGs: a two-track solution. Lancet, 386, $221-222$.

13. Sharma S. 2015. From Aspirations to Reality: How to Effectively Measure the Sustainable Development Goals. Available: http://www.huffingtonpost.com/sheetalsharma/measuring-the-peoples-age_b_7999640.html [Accessed January 20 2016].

14. World Health Organization. 2012. Trends in maternal mortality: 1990 to 2010; WHO, UNICEF, UNFPA and The World Bank estimates. Geneva: World Health Organization.Available: http://www.who.int/reproductivehealth/publications/monitoring/9789241503631/en/ [Accessed January 12 2016]

15. Ministry of Health and Popualtion/Nepal Health Sector Support Program. 2012. HumanResources for Health Strategic Plan 2011-2015 Draft. Kathmandu: Ministry of Health and Popualtion.Available: http://www.who.int/workforcealliance/countries/Nepal_HRHStrategicPlan_finaldraft.pdf [Accessed January 20 2016]. 